\title{
Environmental influences on healthcare expenditures: an exploratory analysis from Ontario, Canada
}

\author{
M Jerrett, J Eyles, C Dufournaud, S Birch
}

J Epidemiol Community Health 2003;57:334-338

See end of article for authors' affiliations

\section{Correspondence to:} Professor M Jerrett, School of Geography and Geology, Health Studies Program, and Institute of Environment and Health, McMaster University, Hamilton, Ontario,

Canada L8S 4L8; jerrettm@mcmaster.ca

Accepted for publication 26 September 2002

\begin{abstract}
Study objective: This paper explores the relation between healthcare expenditures (HCEs) and environmental variables in Ontario, Canada.

Design: The authors used a sequential two stage regression model to control for variables that may influence HCEs and for the possibility of endogenous relations. The analysis relies on cross sectional ecological data from the 49 counties of Ontario.

Main results: The results show that, after control for other variables that may influence health expenditures, both total toxic pollution output and per capita municipal environmental expenditures have significant associations with health expenditures. Counties with higher pollution output tend to have higher per capita HCEs, while those that spend more on defending environmental quality have lower expenditures on health care.

Conclusions: The implications of our findings are twofold. Firstly, sound investments in public health and environmental protection have external benefits in the form of reduced HCEs. Combined with the other benefits such as recreational values, investments in environmental protection probably yield net social benefits. Secondly, health policy that excludes consideration of environmental quality may eventually result in increased expenditures. These results suggest a need to broaden the cost containment debate to ensure environmental determinants of health receive attention as potential complements to conventional cost control policies.
\end{abstract}

rea he purpose of this paper is to explore the relation between healthcare expenditures (HCEs) and environmental variables. Recent public health disasters of environmental origin such as the Escherichia coli O157:H7 outbreak in Walkerton, Ontario-which killed seven people and made more than 2000 others ill $^{1}$-have rekindled interest in the linkage between environmental quality, government policies, and social costs. The costs of environmental contamination are multifaceted and potentially include increased HCEs. ${ }^{2}{ }^{3}$ Relations among environmental conditions, government policies to protect public and ecosystem health, and healthcare costs connect to a larger debate on cost containment in the healthcare system.

Concern over cost containment now drives many health reform policies. ${ }^{4-6}$ In Canada, these concerns have led to reforms aimed at containing healthcare costs by various methods: firstly, by imposing expenditure caps on the physician services expenditures within provincial health budgets ${ }^{7}$; secondly, by constraining the incomes of some physicians through individual physician income caps combined with graduated fee penalties; thirdly, by re-evaluating whether certain procedures should be included or removed from the government fee schedule ${ }^{8}$; fourthly, by assessing whether care givers with less training and lower wages can deliver medically necessary procedures, especially in "underserviced" areas such as rural communities'; and fifthly, by cutting federal transfer payments for health care, which seems to lead to a higher ratio of private to public provision. ${ }^{10}$ In the reforms mentioned, the question of whether societal investments in environmental protection lead to reduced health expenditures remains largely unaddressed. In this paper, we examine the question of whether environmental factors contribute to variation in health expenditures.

\section{METHODS}

The study area consists of the 49 regions, counties, and districts of Ontario. These are coterminous with the census divisions used by Statistics Canada and for convenience are called "counties". Data for the response variable, per capita HCEs, were extracted from public documents. ${ }^{11}{ }^{12}$ Data for other variables were derived from the 1991 census of Canada, ${ }^{13}$ the Municipal Financial Information System, ${ }^{14}$ and the National Pollutant Release Inventory. ${ }^{15}$

\section{Overview of the study design}

Earlier research indicates that current HCEs might be a function of many variables ${ }^{16}$ including: per capita gross domestic product (GDP) ${ }^{17-19}$ household income, ${ }^{20}$ demographic dependency ratios, amount of foreign aid, level of urbanisation, ${ }^{1621}$ ratio of public to private spending on health care, ${ }^{10}$ density of physicians, ${ }^{22}$ and past HCEs. Biophysical environmental variables and those measuring the societal response to environmental degradation are absent from previous analyses, although growing evidence suggests environmental degradation causes some decline in the human population health and in other species on which humans depend for food and resources. ${ }^{23-33}$ The evidence on the environment-health link is strong enough to warrant research that tests the potential influence of these environmental variables on HCEs. ${ }^{2}$ Furthermore, other variables influence population health (for example, educational attainment, economic security, social support), and the potential influence of these variables must be controlled in analyses that test associations between HCEs and environmental variables.

We have attempted to capture the complex system that determines expenditures in a sequential two stage regression analysis. Our modelling controls for the endogenous relation between past HCEs and mortality (a proxy for relative need among populations) and the influence of mortality on current expenditures. We also control other influences on HCEs to prevent confounding in the relation between HCEs and environmental variables.

In Stage 1, we specify the variables that affect population need (to which the medical care system responds) defined as 
age adjusted mortality ratios. Other studies show this measure is a good proxy for health care need, ${ }^{34}$ especially in the Canadian context. ${ }^{35}$ We estimate an equation where age standardised mortality ratios are regressed on population health determinants and on past HCEs (in this case, lagged from the previous budget year, 1990-91). This first equation yields predicted standardised mortality ratios that account for past expenditures and current determinants of population health. We argue that the predicted mortality rates are representative of the current health status, having accounted for past variations in HCEs on a local basis.

The predicted values from Stage $\mathrm{l}$ are entered as an independent variable in a model that uses 1991-92 health care expenditures as the dependent variable in Stage 2. We also include the supply of physicians per county and an indicator variable representing teaching hospitals as likely determinants of current expenditures. Two environmental variables are included in the second stage: total toxic pollution output per county and broadly defined environmental expenditures made by municipal governments. Implicitly we assume an unmeasured morbidity variable intervenes between environmental variables and health expenditures. Given the current state of knowledge on the health effects of environmental degradation, it would prove difficult to predict morbidity because the health effects are often synergistic, subtle, and difficult to quantify. This framework, while imperfect, still allows for a reasonable exploration of the association between environmental factors and HCEs. The specification for the variables is given below. This is followed by a brief commentary on the construction of each variable and the expected direction of the relation.

\section{Model specification and expected relations}

Stage 1 uses the following variables:

$\mathrm{Y}_{i 1}=10$ year standardised mortality ratios for men, based on data from 1979 to 1988 , in the $i$ th county;

$\mathrm{X}_{1 i 1}=1990-91$ provincial Ministry of Health expenditures per resident in the $i$ th county;

$\mathrm{X}_{2 i l}=$ prevalence of low income, as a percentage of the total population over 15 , in the $i$ th county;

$\mathrm{X}_{3 i l}=$ median household income in 1991 Canadian dollars in the ith county;

$\mathrm{X}_{4 i l}=$ educational location quotient for the $i$ th county;

$\mathrm{X}_{\text {sil }}=$ primary industry employment location quotient for the $i$ th county;

$X_{6 i 1}=$ manufacturing employment location quotient for the $i$ th county; and

$\mathrm{e}_{i l}=$ residual term for the $i$ th county.

In Stage 1, lagged expenditures (1 April 1990 to 31 March 1991) are used to represent the possible influence of the healthcare system on current health status. Because health expenditures can affect population health and population health needs can affect expenditures, there is an endogenous relation. By incorporating lagged expenditures from the previous year, we estimate the influence of past expenditures on population health needs. The temporal lag ensures the 1990-91 variable is exogenous to the 1991-92 variables, and this serves as an instrumental variable in that these expenditures can affect our dependent variable of interest (that is, 1991-92 expenditures) but cannot be affected by them. ${ }^{38}$

Socioeconomic conditions in Stage 1 are represented by the incidence of low income relative to the average family, which proxies for inequality; an educational location quotient that measures the proportion of the adult population that exceeds a high school education in each county compared with the provincial adult population proportion; and median household income variable. ${ }^{37}{ }^{39}$ (See Jerrett $e t a^{37}{ }^{39}$ for detailed derivations of the variables.) Based on the findings of population health research, ${ }^{37}{ }^{40-42}$ we expect education and household income variables to relate negatively to mortality, while the low income variable should have a positive relation.
Employment structures can influence population health. We have chosen primary industry as an indicator of dangerous and insecure work, and we expect this variable to relate positively to mortality. ${ }^{43}$ Manufacturing employment represents safer work environments and generally more stable employment. Both anticipation of unemployment and unemployment itself can adversely affect health or health behaviours. ${ }^{45}$ Based on these and other Canadian findings, ${ }^{46}{ }^{47}$ we expect manufacturing to relate negatively to mortality. ${ }^{37}$

Stage 2 includes the following variables:

$\mathrm{Y}_{i 2}=1991-92$ provincial health expenditures per person in the ith county;

$\mathrm{Y}_{i l}=$ predicted male mortality (from Stage 1) for 1991 in the ith county;

$\mathrm{X}_{\mathrm{Ii2}}=$ location quotient of general practitioners and family physicians for the $i$ th county;

$\mathrm{X}_{2 i 2}=$ an indicator variable representing the presence of a teaching hospital in the $i$ th county;

$\mathrm{X}_{3 i 2}=$ municipal environmentally defensive expenditures per resident, in 1991 Canadian dollars, in the ith county; and

$X_{4 i 2}=$ total toxic pollution emissions to all environmental media, in metric tonnes, in the $i$ th county.

$\mathrm{e}_{i 2}=$ residual term in the $i$ th county.

We include two variables to measure possible supply influences on current health expenditures along with predicted mortality to estimate the need for expenditures. A physicians location quotient, measured as the ratio of family physicians per 1000 residents in the county over the comparable rate through the entire province, is used to estimate the relative availability of medical services. ${ }^{37}$ The county units of analysis leave open the possibility that patients from one county may seek medical services in another county, particularly for specialised treatments. Large teaching hospitals are more likely to have specialists that draw patients from other counties. Such movement toward specialists must be accounted for in the model, and we have done so with the teaching hospital indicator variable. Furthermore, we expect these facilities to retain more highly paid physicians and more expensive capital equipment than other hospitals resulting in a positive relation with expenditures. ${ }^{48}$

We have included two variables as measures of environmental quality and protection. The first measures total pollution emissions and is derived from Environment Canada's National Pollutant Release Inventory. ${ }^{15}$ These data estimate total toxic pollution from sources emitting over 10 tonnes per year and were extensively checked for locational and typographical errors. $^{39}$ The second includes expenditures made by all municipal governments in a county to defend environmental quality. These broadly defined expenditures incorporate sewer and water works, waste management, emergency planning, and recreational facilities, all supplied through the municipal budget. ${ }^{49}$ In Canada, these municipal expenditures account for more than $60 \%$ of total environmental expenditures. ${ }^{49}$

We manually selected the model in Stage 1 based on evaluation of the Mallow's Cp statistic, the adjusted $r^{2}$, the standard error of model prediction, and theoretical considerations. The models were fit using ordinary least squares estimation, and variables were transformed to approximate Gaussian normality. In Stage 2, we tested variables together in a multivariate model.

\section{RESULTS}

Figure 1 shows a map of the 1991-92 per capita expenditures in the 49 counties of the study area. The map illustrates that considerable variation in HCEs exists throughout the Province, ranging from a low of $\$ 723$ in Haliburton county to a high of \$2960 in Frontenac county. Counties with teaching hospitals are in the highest category. 


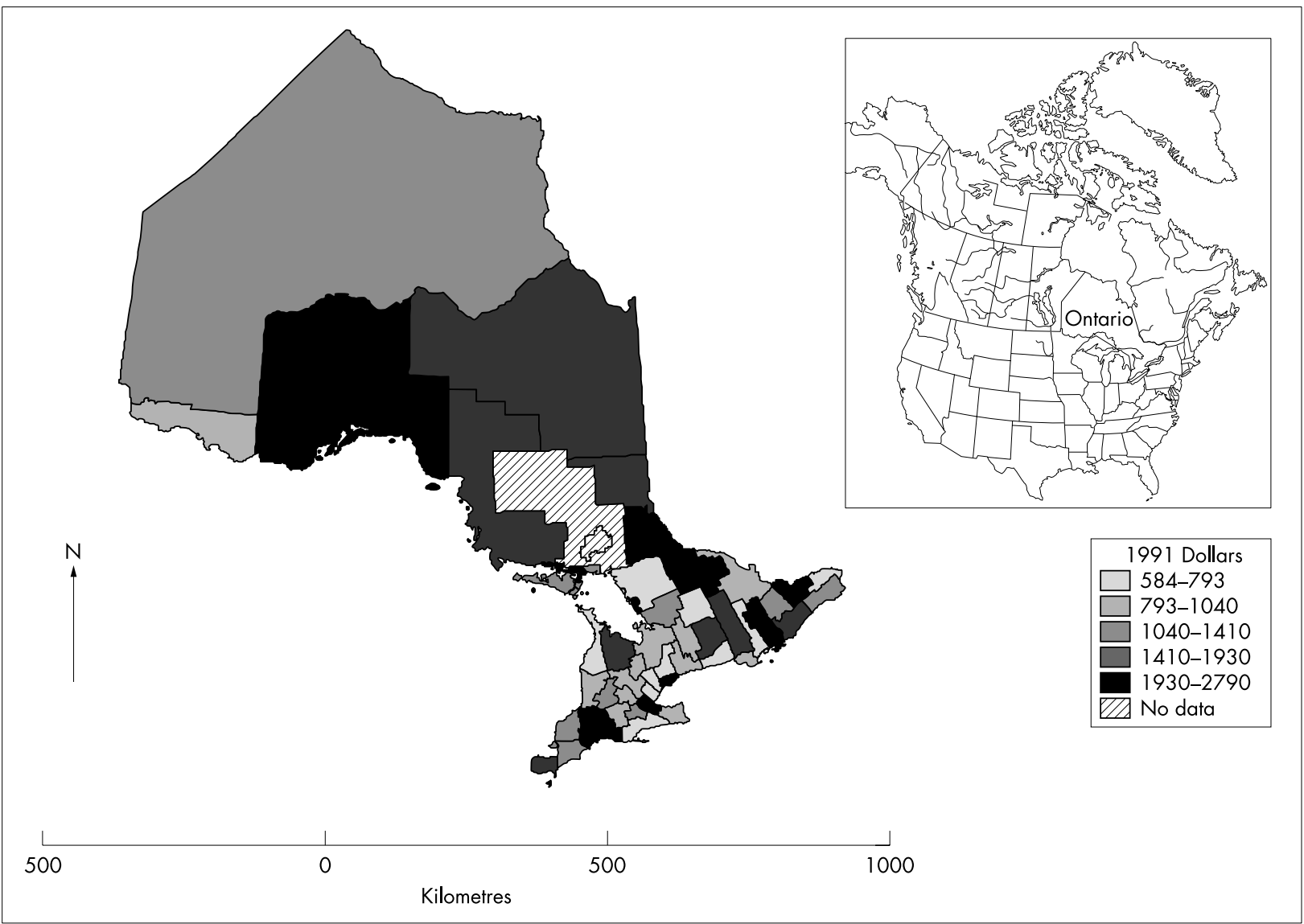

Figure 11991 per capita health expenditures.

Table 1 shows the results from both stages of the model. In Stage 1, there are four significant variables: per capita health expenditures 1990-91, education, manufacturing, and primary industry. These variables are associated with $65 \%$ of the variation in male mortality. Other variables were tested, but found to be insignificant. To minimise collinearity, we removed insignificant variables from this stage. All significant health determinant variables take the expected sign. The lagged health expenditures coefficient takes a positive sign, which probably would not indicate that past expenditures have contributed to increased population mortality. Instead, it may suggest that some aspects of the medical care system have responded to population need, or that through some historical accident, the location of those in need coincides with the location of physicians or medical expenditures.

In Stage 2, we used predicted mortality as an independent variable along with a physicians location quotient, an indicator variable for teaching hospitals, and the environmental variables. The predicted mortality variable (representing population need adjusted for past expenditures) shows a positive, significant relation with current expenditures. The teaching hospital variable is highly significant, but the physician variable is insignificant. This variable may be insignificant because of the mortality and hospital variables adequately represent supply of and need for HCEs. The results show that both toxic pollution and municipal defensive expenditures

\begin{tabular}{|c|c|c|c|c|c|c|}
\hline Variable & Coefficient & SE & $t$ Value & Prob $>t$ & VIF & Partial $r$ \\
\hline \multicolumn{7}{|c|}{ Stage 1 Predicting mortality as a proxy for need controlling for past expenditures } \\
\hline Constant & 205.51 & 20.42 & 16.74 & 0.000 & & \\
\hline Health expend $t-1$ & 0.011544 & 0.004556 & 2.53 & 0.015 & 1.1 & 0.36 \\
\hline Education & -101.24 & 21.24 & -4.77 & 0.000 & 1.7 & -0.59 \\
\hline Primary industry* & 4.72 & 2.13 & 2.22 & 0.032 & 1.4 & 0.32 \\
\hline $\begin{array}{l}\text { Manufacturing } \\
\text { Adj } r^{2} 65.4 \%\end{array}$ & -17.07 & 6.27 & -2.72 & 0.009 & 2.0 & -0.39 \\
\hline \multicolumn{7}{|c|}{ Stage 2 Predicting current expenditures } \\
\hline Constant & 2604.25 & 1295.50 & 2.01 & 0.051 & & \\
\hline Predicted mortality & 10.88 & 2.52 & 4.32 & 0.000 & 1.1 & 0.56 \\
\hline Teaching hospital & 1092.14 & 121.82 & 8.97 & 0.000 & 1.6 & 0.81 \\
\hline Toxic pollution* & 45.43 & 12.87 & 3.53 & 0.001 & 1.2 & 0.48 \\
\hline $\begin{array}{l}\text { Environ expend* } \\
\text { Adj } r^{2} \text { sq } 67.1 \%\end{array}$ & -431.54 & 204.86 & -2.11 & 0.041 & 1.2 & -0.31 \\
\hline
\end{tabular}




\section{Key points}

- Previous research on the determinants of healthcare expenditures has excluded environmental variables.

- In Ontario total toxic pollution output relates positively and per capita municipal environmental expenditures relate negatively to healthcare expenditures.

- Sound investments in public health and environmental protection may have external benefits in the form of reduced healthcare expenditures.

- Environmental determinants of health should receive attention as potential complements to conventional health care cost control policies.

have a significant relation with current health expenditures. Total toxic pollution output is positively related to health expenditures, while municipal defensive expenditures are negatively related. All four significant variables account for $67 \%$ of the variation in current health expenditures. We tested the unstandardised residuals for spatial autocorrelation with the Moran's I. The results showed a negative coefficient $(-0.17)$ with no significant autocorrelation $(p>0.1)$. Visual inspection of the mapped residuals revealed no unusual patterns. Thus the assumption of independent observations required for efficient and unbiased OLS estimation seems to be fulfilled.

We transformed both environmental variables with the natural log because of a strong positive skew, so the coefficients are interpreted as $\mathrm{b} / \mathrm{Y}_{2 \text { mean }}$. Using this method, the results show that one tonne higher pollution, evaluated at the mean value of expenditures, associates with a 0.03 dollars or 3 cents higher per capita health expenditures. A one dollar increase in defensive expenditures is associated with health expenditures that are 31 cents lower per capita and are not accounted for by the mortality in a population or the presence of teaching hospitals. Interpretation of the coefficient times the range of data shows the magnitude of impact from the highest to the lowest county value. This analysis suggests pollution could exert a $\$ 355$ difference in per capita health expenditures, when the lowest pollution level is compared with the highest level ( 0.03 dollars per tonne $\times$ range of 10800 tonnes $=\$ 355$ ), while health expenditures would be about $\$ 200$ lower based on a comparison of the lowest to the highest defensive expenditures $(\$-0.31 \times$ range of $\$ 644=\$-200)$.

\section{DISCUSSION}

Our results show that, after control for other variables that influence health expenditures, both total toxic pollution output and per capita municipal environmental expenditures have significant associations with HCEs. Counties with higher pollution output tend to have higher per captia HCEs, while those that spend more on defending environmental quality have lower HCEs. The implications of this finding are twofold. Firstly, investments in environmental protection are likely to yield external benefits in the form of reduced HCEs. Given other benefits associated with environmental expenditures such as recreation values and maintaining the health of other species, municipal expenditures in environmental protection probably yield net social benefits (that is, expenditures of one dollar yield a benefit greater than one dollar).

Secondly, health policy that excludes considerations of environmental quality may result in increased HCEs, which then "crowd out" other socially beneficial investments. This relation may set in motion a cycle of cumulative consequences whereby environmental degradation leads to higher health expenditures which in turn reduce funds available for environmental protection thus leading to more degradation and so on. In theory, this relation will hold, although in the case of Ontario it is complicated by jurisdictional fragmentation. The provincial government makes the majority of health expenditures, and municipal governments spend more than other levels of government on environmental protection. Yet, the role of provincial grants in stimulating municipal environmental expenditures ${ }^{49}$ suggests that crowding out may still be important. Furthermore, many instances exist where crowding out by health expenditures will have a direct influence on provincial environmental programmes. This analysis implies that while many other factors must be taken into account in the cost containment debate, exclusion of environmental considerations may lead to social disbenefits.

This study represents an exploratory attempt to quantify the relation between HCEs and environmental variables, and the findings must be tempered with methodological caveats. Firstly, the comparatively small units of analysis used here may lead to possible spillover effects in environmental externalities. Enhanced environmental programmes and expenditures in one jurisdiction would be negated if neighbouring regions pursue environmentally damaging policies. We were unable to address this issue directly, but the lack of spatial autocorrelation in the residuals suggests the variables included in our regression models account for spillovers. If this were not the case, we would expect to see some residual autocorrelaton.

Secondly, time lags may influence the relations among environmental investments, environmental quality, and health expenditures. For example, environmental expenditures may not immediately improve environmental quality. Improvements in environmental conditions may take some time to influence health. In turn, improvements in health may not affect demand for health services because of lags in physician, patient, or administrative practices. The direct trade off between environmental and health expenditures as shown in our analysis of the regression coefficients probably overstates our ability to predict these complex relations.

Future research using micro-level data relating specific types of spending (for example, traffic pollution reductions) to individual ill health (for example, asthma) would perhaps better capture the complex environment-health relations explored in this ecological analysis. These refinements seem worth pursuing now that this initial research has established the possibility of a relation between environmental variables and HCEs.

\section{ACKNOWLEDGEMENTS}

We thank an anonymous reviewer and the editor for comments that improved the paper. We also thank Pat De Luca and Ric Hamilton for assistance with preparing the map. Moe Watkin of the Ontario Ministry of Health and Long Term Care supplied the health expenditures data and gave useful clarifying comments on its use.

\section{Endnotes}

(1) SMR data were extracted from previous studies. ${ }^{37}$ The long run of mortality data is used to proxy need in 1991. We expect this variable to be representative of the long term mortality pattern and hence adequate for measuring need in 1991. Correlations with female mortality rates are quite high, $r=0.87, \mathrm{p}<0.001$, but male rates were found to correlate more closely with socioeconomic health determinants, ${ }^{37}$ so we have used these rates for the purpose of generating a predicted value for Stage 2 .

(2) Data extracted from Ministry of Health ${ }^{11}{ }^{12}$ and based on "Part I" classification that includes operation of hospitals and related facilities, Ontario Health Insurance Plan billings, long term care, mental health services, ambulatory and emergency services, and other primary care services. For the 1991-92 budget year, Part I expenditures accounted for $\$ 15966796256$ of $\$ 16525215022$ total expenditures or about $96.6 \%$ of the total.

(3) Data for the Region and District of Sudbury are combined by the Ministry of Health in expenditures reports. Because we were unable to discern which proportion of the expenditures was attributable to each county, we had to eliminate both cases, leaving 47 counties in the final analysis. 


\section{Authors' affiliations}

M Jerrett, J Eyles, School of Geography and Geology, Health Studies Program, and Institute of Environment and Health, McMaster University, Hamilton, Ontario, Canada

C Dufournaud, Department of Geography, University of Waterloo, Canada

S Birch, Department of Clinical Epidemiology and Biostatistics and Centre for Health Economics and Policy Analysis, McMaster University

Funding: this research was funded by the McMaster Institute of Environment and Health and the Geographic Information Science Health and Environmental Analysis Laboratory, McMaster University.

Conflicts of interest: none.

\section{REFERENCES}

1 Health Canada. Waterborne outbreak of gastroenteritis associated with a contaminated water supply, Walkerton, Ontario, May-June 2000. Ottawa: Canada Communicable Disease Report, 2000,26:170-3.

2 Ontario Medical Association. The illness cost of air pollution: summary of findings. Toronto: Ontario Medical Association, 2000.

3 Pearce D, Turner KR. Economics of natural resources and the environment. Baltimore: Johns Hopkins Press, 1991.

4 Lomas J. Devolving authority for health care in Canada's provinces: 4. Emerging issue and prospects. Can Med Assoc J 1997; 156:817-23.

5 Barer ML, Evans RG, Holt $M$, et al. It ain't necessarily so: the cost implications of health care reform. Health Aff 1994;13:88-99.

6 Chernomas R, Sepehri A. An economist's brief guide to the recent debates on the Canadian health care system. Int J Health Serv 1994;24:189-200

7 Hurley J, Lomas J, Goldsmith L. Physician responses to global physician expenditure budgets in Canada: a common property perspective. Milbank Q 1997; 75:343-62.

8 Barer ML, Lomas J, Sanmartin C. Re-minding our Ps and Qs: medical cost controls in Canada. Health Aff 1996;15:216-34.

9 Barer ML, Stoddart GL. Toward integrated medical resource policies for Canada: 8. geographic distribution of physicians. Can Med Assoc J 1992:147:617-23

$10 \mathrm{Di}$ Matteo L. The determinants of the public-private mix in Canadian health care expenditures: 1975-1996. Health Policy 2000;52:87-1 12

11 Ministry of Health, Information and Planning Branch. Ontario health expenditures 1990/91: analysis of expenditures by major programs, counties and health districts. Toronto: Community Information Section of the Information, Planning and Evaluation Branch, 1992.

12 Ministry of Health, Information and Planning Branch. Ontario health expenditures 1991/92: analysis of expenditures by major programs, counties and health districts. Toronto: Community Information Section of the Information, Planning and Evaluation Branch, 1993.

13 Statistics Canada. Data documentation for the 1991 census profile series-part A or B. Ottawa: Supply and Services Canada, 1991

14 Ministry of Municipal Affairs. Municipal financial information 1991 Ottawa: Queen's Printer for Ontario, 1993.

15 Environment Canada. National pollutant release inventory data base. 1995 (available http://www.doe.ca/pdb/npri.html).

16 Di Matteo L, Di Matteo R. Evidence on the determinants of Canadian provincial government health expenditures: 1965-1991. J Health Econ 1998:17:211-29.

17 Newhouse JP. Medical care expenditures: a cross-national survey Journal of Human Resources 1977;12:115-25.

18 Hitris T, Posnett J. The determinants and effects of health expenditure in developed countries. J Health Econ 1992;11:173-81.

19 Parkin D, McGuire A, Yule B. Aggregate health care expenditures and national income: Is health care a luxury good? J Health Econ 1987;6:109-27.

20 Evans RG, Stoddart GL. Producing health, consuming health care. Soc Sci Med 1990;31:1347-63.

21 Hansen $\mathbf{P}$, King A. The determinants of health care expenditure: a cointergration approach. J Health Econ 1996;15:127-37.
22 Birch S. The identification of supplier-inducement in a fixed price system of health care provision: the case of dentistry in the United Kingdom. J Health Econ 1988;7:129-50.

23 Burnett RT, Dales RE, Raizenne MB, et al. Effects of low ambient levels of ozone and sulfates on the frequency of respiratory admissions to Ontario hospitals. Environ Res 1994;65:172-94.

24 Burnett RT, Dales R, Krewski D, et al. Associations between ambient particulate sulfate and admissions to Ontario hospitals for cardiac and respiratory diseases. Am J Epidemiol 1994;142:15-22.

25 Geschwind SA, Stolwijk JAJ, Bracken M, et al. Risk of congenital malformations associated with proximity to hazardous waste sites. Am J Epidemiol 1992;135: 1197-207.

26 Davis DL, Dinse GE, Hoel DG. Decreasing cardiovascular disease and increasing cancer among whites in the United States from 1973 through 1987: good news and bad news. JAMA 1994;271:431-7.

27 Patrick DL, Wickizer TM. Community and health. In: Amick B, Levine S, Tarlov A, et al, eds. Society and health. New York: Oxford University Press, 1995:46-92.

28 Colborn T, vom Saal FS, Soto AM. Developmental effects of endocrine disrupting chemicals in wildlife and humans. Environ Health Perspect 1993;101:378-83.

29 Eyles J. Environmental health research: setting an agenda by spinning our wheels or climbing the mountain? Health and Place 1997;3:1-13.

30 Krewski D, Burnett R, Goldberg MS, et al. Reanalysis of the Harvard Six-Cities Study and the American Cancer Society Study of Air Pollution and Mortality, Phase II: Sensitivity Analysis. Cambridge, MA: Health Effects Institute, 2000:295.

31 Eyles J, Elliott SJ. Global environmental change and human health. Canadian Geographer 2001;45:99-104.

32 Kunzli W. Assessment of deaths attributable to air pollution: Should we use risk estimates based on time series or cohort studies? Am J Epidemiol 2001;153:1050-5.

33 Health Canada. The health and environment handbook for health professionals. Ottawa: Minister of Public Works and Government Services Canada, 1998

34 Birch S, Eyles J, Hurley J, et al. A needs-based approach to resource allocation in health care. Can J Public Policy 1993;19:68-85.

35 Eyles J, Birch S. A population needs-based approach to health care resource allocation and planning in Ontario. Can J Public Health 1993;84:112-17

36 Eyles J, Birch S, Chambers S, et al. A needs-based methodology for the allocation of health care resources in Ontario. Soc Sci Med 1999;33:489-500.

37 Jerrett, $M$, Eyles J, Cole D. Socioeconomic and environmental covariates of premature mortality in Ontario. Soc Sci Med 1998;41:33-49.

38 Kennedy P. A guide to econometrics. Cambridge, MA: MIT Press, 1994:411.

39 Jerrett $M$, Eyles J, Cole D, et al. Environmental equity in Canada: an empirical investigation into the income distribution of pollution in Ontario. Environ Plann A 1997;29:1777-800.

40 Menchik, PL. Economic status as a determinant of mortality among black and white older men: Does poverty kill? Popul Stud 1993:47:427-36.

41 Feinstein FS. The relationship between socioeconomic status and health: a review of the literature. Milbank Q 1993;71:279-322.

42 Kunst AE, Mackenbach JP. The size of mortality differences in nine industrialized countries. Am J Public Health 1994;84:932-7.

43 Marshall KM. A job to die for. Perspectives on labour and income. BM 1996;311:26-31

44 Ferrie JE, Shipley M, Marmot MG, et al. Health effects of anticipation of job change and non-employment: longitudinal data from the Whitehall study. BM 1995;311:1264-9.

45 Dooley D, Catalano R, Wilson G. Depression and unemployment: pane findings from the epidemiologic catchment area study. Am J Community Psychol 1994;22:745-65.

46 Liaw K, Wort SA, Hayes MB. Intraurban mortality variation and income disparity: a case study of Hamilton-Wentworth region. Canadian Geographer 1989;33:131-45

47 D'Arcy C. Unemployment and health: data and implications. Can J Public Health 1986;77:124-31.

48 UK Department of Health and Social Services. Sharing resources for health in England. London: HMSO, 1976.

49 Jerrett $\boldsymbol{M}$. Green costs, red ink: determinants of municipal defensive expenditures. Professional Geographer 1999;51:115-34. 